\title{
PAPEL ESTRUTURANTE DAS RIMAS EM SONETOS *
}

\section{Renira Lisboa de Moura Lima ${ }^{*}$}

Resumo: Comprova-se, em sonetos de diversos autores e de diferentes estilos de época, o poder estruturante das rimas quer quanto à consonância, quer quanto à tonicidade, pela análise da estrutura do texto e pela possibilidade de reescrita da composição.

Palavras-chave: Esquema rimático; rimas quanto à consonância; rimas quanto à tonicidade; soneto; soneto francês; soneto italiano

O estudo da utilização e distribuição das rimas leva à compreensão da importância desse instrumento sonoro e lingüístico, de reconhecido valor mnemônico, pela dupla função que exerce na composição do soneto: delimitação de verso e de estrofe e organização textual. O esquema rimático se liga tanto à organização da estrofe, como na oitava rima - abababcc -, em que três ccos rimáticos se dispõem em rimas cruzadas nos seis primeiros versos e em rimas emparelhadas nos dois últimos, como se um sexteto se combinasse a um dístico, quanto à configuração do próprio poema, como comprova o esquema abba, abba, cdc, dcd, utilizado em uma das formas italianas do soneto (MOLINO; GARDES-TAMINE, 1992, p. 78), contribuindo, assim, para o seu equilíbrio rímico.

No entanto, apesar de serem respeitadas as exigências estruturais da língua utilizada, a elas se sobrepõem, predominantes, as exigências dos esquemas métrico e rímico, de que vão decorrer as chamadas "licenças poéticas", em diversos níveis, como o

Artigo adaptado do capitulo homônimo do livro A forma soneto, em fase de edição.

* Professora Adjunta do antigo Departamento de Letras Clássicas e Vernáculas, da Universidade Federal de Alagoas. Livre docente em Ensino da Língua Portuguesa pela Universidade Federal de Alagoas. Mestre em Educação pela Universidade Federal da Bahia. 
deslocamento da sílaba tônica, figura de dicção chamada de hiperbibasmo, como fez Castro Alves, na primeira estrofe do Canto II do poema "Pedro Ivo" (ALVES, 1997, p. 55-63), em que usa a forma órgia [orgia], recuando a sílaba tônica para a sílaba anterior (sístole), para que pudesse rimar com a palavra antecedente Geórgia e e a subseqüente Bórgia; ou como a inclusão de uma palavra (se) para completar a medida do verso, figura de construção conhecida como rípio, ou cavilha, como no segundo verso de segundo quarteto do conhecido soneto Hão de chorar por ela os cinamomos, de Alphonsus de Guimaraens: "Pois ela se morreu silente e fria..." (apud CARRETER; LARA, 1962, p. 144).

\section{Tipos de segmentação}

Com efeito, no soneto, como ocorre com as formas fixas de um modo geral, o esquema rímico preestabelecido tem um papel eminentemente estruturador, podendo os versos, por meio de atividades de reescrita, ser reunidos ou separados, obtendo-se outras distribuições estróficas e configurações tipográficas, correspondentes a uma segmentação bipartida, tripartida ou quadripartida.

\section{Segmentação bipartida}

Pelo esquema rímico e pela possibilidade de reorganizar-se sua estrutura tipográfica, as formas canônicas do soneto italiano e francês, ainda hoje, podem ser consideradas como uma composição constituída de duas partes, determinadas pelo jogo fônico e representadas por uma estrutura biestrófica, que permanece fiel à forma primitiva do soneto sistematizado por Petrarca - uma oitava (os dois quartetos) e um sexteto (os dois tercetos) -, estabelecendo-se, entre os seus versos, uma razão de $8: 6$ (ou $4: 3$, numa forma simplificada).

Essa segmentação biestrófica do soneto é importante tanto do ponto de vista formal, quanto do ponto de vista psicológico. Do ponto de vista formal, a primeira parte, apesar de mais longa (oito versos), tem um menor número de rimas (dois ecos rimáticos), estabelecendose uma razão de $1: 4$, ou seja, uma rima diferente para quatro versos. Entre um quarteto e outro, dada a autonomia sintática de cada um deles, há uma pausa obrigatória, mas uma pausa atenuada, motivada 
pela reiteração do esquema rimático do quarteto, em que se liga, pela consonância, o último verso do primeiro quarteto ao primeiro verso do segundo. Do ponto de vista psicológico, essa primeira parte é estática. A segunda parte, mais curta, com seis versos, tem um maior número de rimas (três ecos rimáticos), numa razão de $1: 2$, isto é, uma rima para cada dois versos. Essa parte, como acontece com a composição musical, muda de tom e de andamento, sendo, pois, dinâmica, do ponto de vista psicológico.

O soneto, pois, apresenta uma desproporção entre as duas partes: nos sonetos italiano e francês, a razão existente entre as duas partes é de $4: 3$ (oito versos na primeira e seis, na segunda); no soneto inglês, de $6: 1$ (doze versos na primeira e dois, na segunda). Essa distribuição fez com que Banville (apud MOLINO; GARDESTAMINE, 1988, p. 103) reconhecesse que o soneto só não se torna uma figura grotesca - de busto enorme e de pernas curtas e finas graças ao artifício dos poetas que corrigem essa estrutura, atenuando, ou até mesmo acentuando essa característica, passando a ser uma forma "magnífica e bela".

Essa diferença na proporção possibilita a mudança do andamento das duas partes - mais lento e mais pomposo, no conjunto dos quartetos; mais rápido, mais allegro no conjunto de tercetos ou no dístico -, estabelecendo-se, dessa forma, uma tensão na articulação da idéia desenvolvida, como defende o poeta português Nuno Júdice (*1949), em entrevista dada a Martins (2005, p. 7): "Tal como numa peça musical também um poema necessita de várias velocidades e de vários andamentos".

As restrições formais do soneto, que não permitem repetição de estrofes ou de versos sob a forma de refrão, estribilho ou bordão, fazem com que essa forma poética se preste à criação de um conjunto de efeitos semântico-estilísticos estabelecidos por analogias e constrastes, eliminando-se a monotonia da composição. Nas formas italiana e francesa, nos quartetos e nos tercetos se apresentam idéias diferentes, sob a forma de antíteses, analogias, comparações ou deduções; na forma inglesa, segue-se às variações de um mesmo tema, apresentadas nos quartetos, e o fechamento contém, no dístico, uma generalização, em forma de uma declaração afirmativa ou negativa. 
Assim, a fusão das partes contidas nos quartetos e nos tercetos, ou nos quartetos e no dístico, adapta-se adequadamente aos estágios do desenvolvimento do tema selecionado - na avaliação de Nóbrega (1965, p. 38) o soneto é um milagre do engenho poético do ser humano - permitindo jogos de oposição e de paralelismo, muitas vezes entre o comparante e o comparado, o que se comprova com o Exemplo 1.

Exemplo 1

\begin{tabular}{|c|c|c|}
\hline \multicolumn{3}{|l|}{ AS POMBAS } \\
\hline Vai-se a primeira pomba despertada... & $\mathrm{a}$ & $\mathrm{F}$ \\
\hline Vai-se outra mais... mais outra... enfim dezenas & $\mathrm{b}$ & $\mathrm{F}$ \\
\hline De pombas vão-se dos pombais, apenas & $\mathrm{b}$ & $\mathrm{F}$ \\
\hline Raia sangüínea e fresca a madrugada... & $\mathrm{a}$ & $\mathrm{F}$ \\
\hline E à tarde, quando a rígida nortada & $\mathrm{a}$ & $\mathrm{F}$ \\
\hline Sopra, aos pombais de novo elas, serenas, & $\mathrm{b}$ & $\mathrm{F}$ \\
\hline Ruflando as asas, sacudindo as penas, & $\mathrm{b}$ & $\mathrm{F}$ \\
\hline Voltam todas em bando e em revoada... & $\mathrm{a}$ & $\mathrm{F}$ \\
\hline Também dos corações onde abotoam. & $\mathrm{c}$ & $\mathrm{F}$ \\
\hline Os sonhos, um por um, céleres voam, & $\mathrm{c}$ & $\mathrm{F}$ \\
\hline Como voam as pombas dos pombais; & d & M \\
\hline No azul da adolescência as asas soltam, & $\mathrm{e}$ & $\mathrm{F}$ \\
\hline Fogem... Mas aos pombais as pombas voltam, & $\mathrm{e}$ & $\mathrm{F}$ \\
\hline E eles aos corações não voltam mais. & $\mathrm{d}$ & M \\
\hline \multicolumn{3}{|l|}{$\begin{array}{l}\text { Raimundo Correia (1859-1911) } \\
\text { (IVO, 1958, p. 22) }\end{array}$} \\
\hline
\end{tabular}

Passa-se do registro de um fato observável - a partida das pombas -, assunto da primeira parte (quartetos com autonomia sintática e dois ecos rimáticos distribuídos em rimas abraçadas, dos quais o primeiro (a) inicia e arremata a estrofe) - para a reflexão sobre a fugacidade dos sonhos, patente na segunda parte, formada pelos tercetos, sem autonomia sintática isoladamente, com três ecos rimáticos, dois dos quais, dispostos em rimas emparelhadas iniciais intra-estróficas, marcam o início de estrofe, e o terceiro, interestrófico, se repete como fechamento de estrofe e da composição.

Embora, na distribuição rímica, haja coincidência na consonância e na tonicidade, é a tonicidade que delimita mais precisamente essas partes: na primeira, só aparecem rimas femininas, 
ou graves; na segunda, as rimas iniciais, emparelhadas, são femininas, mas as rimas dos últimos versos são masculinas, ou agudas, delimitando-se, assim, tanto o verso final dos tercetos quanto a própria composição que, no entanto, se inicia com um verso de rima feminina.

A relação semântica entre essas duas partes se faz por analogia, manifestada por meio de uma articulação lingüística, o conector lógico também. Por isso é que, entre essas duas partes, ou seja, entre o conjunto dos quartetos (oitava) e o conjunto dos tercetos (sexteto), a pausa deve ser bem marcada na leitura e/ou na declamação do soneto, preparando o leitor ou o ouvinte para o efeito dessas mudanças formais .

No esquema rimático do Exemplo 2, bastante simétrico, altamente previsível, as rimas masculinas (eco rimático $a$ ) determinam o limite inicial e final dos quartetos, abraçando as rimas femininas (eco rimático $b$ ), dispostas nos versos centrais.

Exemplo 2

\begin{tabular}{|l|c|c|}
\hline \multicolumn{1}{|c|}{ Quão caro venda Amor um gosto seu } & \multicolumn{2}{c|}{ RIMAS } \\
\hline Quão caro venda Amor um gosto seu, & $\mathrm{M}$ & $\mathrm{a}$ \\
Quão pouco tarda a pena certa e justa & $\mathrm{F}$ & $\mathrm{b}$ \\
Bem o sabe minh'alma e bem lhe custa, & $\mathrm{F}$ & $\mathrm{b}$ \\
Que por um (que não viu) o melhor deu. & $\mathrm{M}$ & $\mathrm{a}$ \\
\hline Milagre foi por certo escapar eu & $\mathrm{M}$ & $\mathrm{a}$ \\
De mar tão furioso, em fraca fusta: & $\mathrm{F}$ & $\mathrm{b}$ \\
Erro seria agora e cousa injusta, & $\mathrm{F}$ & $\mathrm{b}$ \\
Crer nas cousas d'Amor imigo meu. & $\mathrm{M}$ & $\mathrm{a}$ \\
\hline Porque nos laços seus outra vez caia, & $\mathrm{F}$ & $\mathrm{c}$ \\
Hora' finge, hora roga, hora ameaça, & $\mathrm{F}$ & $\mathrm{d}$ \\
Usa de força, e manha, tudo tenta: & $\mathrm{F}$ & $\mathrm{d}$ \\
\hline Mas não me enganará, por mais que faça: & $\mathrm{F}$ & $\mathrm{c}$ \\
Quem do naufrágio sai a nado à praia, & $\mathrm{F}$ & $\mathrm{e}$ \\
Té na terra se teme da tormenta. & Diogo Bernardes (c.1520-c. 1605) \\
\hline \multicolumn{2}{|c|}{ (GRÜNEWALD, 1987, p. 43) } \\
\hline
\end{tabular}

1 Foi mantida a ortografia original. 
Identifica-se a primeira parte em que se apresenta uma experiência vivida e se faz uma promessa, em termos de uma previsão quase profética (uso do futuro do pretérito do modo indicativo seria) de não haver uma recaída provocada pelas tentações do amor. Nos tercetos, porém, sem o jogo da tonicidade e sem autonomia sintática, só se utilizam rimas femininas continuadas. Nessa segunda parte, justifica-se, no primeiro terceto, a situação anteriormente apresentada e analisada, e, no segundo terceto, confirma-se a decisão de não se deixar mais ser enganado pelo jogo traiçoeiro do amor, pela utilização do futuro do presente do modo indicativo (enganará), no primeiro verso, e de uma chave-de-ouro em forma similar a um provérbio, nos dois últimos versos, utilizado o presente indicativo, atemporal (sai, teme).

No Exemplo 3, identificam-se, com reiteração e sobreposição dos esquemas rimáticos de consonância e de tonicidade, uma oitava, de rimas abraçadas (FMMFFMMF, abbaabba) e um sexteto, de rimas cruzadas (FMFMFM cdcded). Pelo jogo de rimas quanto à tonicidade, têm-se identificadas duas partes: a primeira, que contém a cobrança de uma atitude (manifestar brandura), apoiada na promessa de uma fidelidade à "santa lei"; a segunda, que apresenta a justificativa, a razão que força o poeta a ter confiança no amor de Deus e a certeza de sua salvação.

Exemplo 3 (AYALA, 1997, p. 17),

\begin{tabular}{|l|c|c|}
\hline \multicolumn{3}{|c|}{ A CRISTO N. S. CRUCIFICADO, ESTANDO O POETA NA ÚLTIMA } \\
\hline Meu Deus, que estais pendente em um madeiro, & $\mathrm{F}$ & $\mathrm{a}$ \\
Em cuja lei protesto de viver, & $\mathrm{M}$ & $\mathrm{b}$ \\
Em cuja santa lei hei de morrer & $\mathrm{M}$ & $\mathrm{b}$ \\
Animoso, constante, firme, e inteiro. & $\mathrm{F}$ & $\mathrm{a}$ \\
\hline Neste lance, por ser o derradeiro, & $\mathrm{F}$ & $\mathrm{a}$ \\
Pois vejo a minha vida anoitecer, & $\mathrm{M}$ & $\mathrm{b}$ \\
É, meu Jesus, a hora de se ver & $\mathrm{M}$ & $\mathrm{b}$ \\
A brandura de um Pai manso Cordeiro. & $\mathrm{F}$ & $\mathrm{a}$ \\
\hline Mui grande é vosso amor, e meu delito, & $\mathrm{F}$ & $\mathrm{c}$ \\
Porém pode ter fim todo o pecar, & $\mathrm{M}$ & $\mathrm{d}$ \\
E não o vosso amor, que é infinito. & $\mathrm{F}$ & $\mathrm{c}$ \\
\hline Esta razão me obriga a confiar, & $\mathrm{M}$ & $\mathrm{d}$ \\
Que por mais que pequei, neste conflito & $\mathrm{F}$ & $\mathrm{c}$ \\
Espero em vosso amor de me salvar. & $\mathrm{M}$ & $\mathrm{d}$ \\
\hline \multicolumn{2}{|c|}{ Gregório de Matos (c.1633-1696) } \\
\hline
\end{tabular}


Nesse soneto, que apresenta uma argumentação em forma silogística, as três primeiras estrofes têm limite inicial e final determinado por uma rima feminina. Porém, no último terceto estrofe que sintetiza, como justificativa da esperança de salvação, a idéia apresentada nas estrofes anteriores, o que se comprova com a marca de coesão referencial (uso do pronome demonstrativo esta e do item lexical razão) - é a rima masculina que marca os seus limites.

No Exemplo 4, evidencia-se o poder estruturante do jogo das rimas masculinas e femininas, dividindo-se esse soneto francês em duas partes: a primeira, em que se descreve o fato, a situação vivida, o assassinato do filho de Malherbe, é constituída dos quartetos, cuja autonomia sintática só se dá no último verso do conjunto, formando-se uma oitava, delimitada por rimas femininas, que abrem e fecham essa parte, abraçando as rimas masculinas, emparelhadas, centrais. $\mathrm{Na}$ segunda parte, faz-se uma súplica a Deus, um pedido de justiça. É constituída dos tercetos que só adquirem autonomia sintática se vistos como um sexteto cujos limites inicial e final são marcados por rimas masculinas. As rimas masculinas iniciam cada terceto, apresentandose emparelhadas, no primeiro, e cruzadas, no segundo

Exemplo 4

\begin{tabular}{|l|c|c|}
\hline \multicolumn{1}{|c|}{ SUR LA MORT DE SON FILS } & \multicolumn{2}{c|}{ RIMAS } \\
\hline Que mon fils ait perdu sa dépouille mortelle, & $\mathrm{F}$ & $\mathrm{a}$ \\
Ce fils qui fut si brave et que j'aimai si fort, & $\mathrm{M}$ & $\mathrm{b}$ \\
Je ne I' impute point à l'injure du sort, & $\mathrm{M}$ & $\mathrm{b}$ \\
Puisque finir à l'homme est chose naturelle; & $\mathrm{F}$ & $\mathrm{a}$ \\
\hline Mais que de deux marauds la surprise infidèle & $\mathrm{F}$ & $\mathrm{a}$ \\
Ait terminé ses jours d'une tragique mort, & $\mathrm{M}$ & $\mathrm{b}$ \\
En cela ma douleur n'a point de réconfort, & $\mathrm{M}$ & $\mathrm{b}$ \\
Et tous mes sentiments sont d'accord avec elle. & $\mathrm{F}$ & $\mathrm{a}$ \\
\hline O mon dieu, mon Sauveur, puisque, par la raison & $\mathrm{M}$ & $\mathrm{c}$ \\
Le trouble de mon ame étant sans guérison, & $\mathrm{M}$ & $\mathrm{c}$ \\
Le voeu de la vengeance est un voeu legitime, & $\mathrm{F}$ & $\mathrm{d}$ \\
\hline Fais que de ton appui je sois fortifié: & $\mathrm{M}$ & $\mathrm{e}$ \\
Ta justice t'en prie, et les auteurs du crime & $\mathrm{F}$ & $\mathrm{d}$ \\
Sont fils de ces bourreaux qui t'ont crucifié. & $\mathrm{M}$ & $\mathrm{e}$ \\
\hline \multicolumn{2}{|c|}{ François de Malherbe (1555-1628) } & \\
\hline \multicolumn{2}{|c|}{ (LAGARDE; MICHARD, 1959, p.26) } \\
\hline
\end{tabular}


Assim, delimita-se a composição com tonicidade diferente: rima feminina inicial, no primeiro verso, e rima masculina final, no último verso; delimita-se a primeira parte com rimas femininas, e a segunda, com rimas masculinas.A diferença de tonicidade no limite final dos tercetos feminina no primeiro e masculina, no segundo - leva à identificação da estrutura do sexteto composto de um dístico e de um quarteto com rimas cruzadas, disposição que também se verifica tanto nas rimas consonânticas, apresentando-se a composição com uma estrutura triestrófica.

Por sua vez, no Exemplo 5, identificam-se duas partes, ambas delimitadas pela reiteração dos esquemas rimáticos (consonântico e de tonicidade) superpostos: na primeira, a oitava formada dos quartetos, apresenta-se o objeto do amor; na segunda, a justificativa, em forma de credo, com reiteração da forma verbal (creio), como palavra inicial de cada terceto, adotada a anáfora., figura de construção em que se repete uma palavra, expressão ou frase, no início de frases, períodos ou versos (TAVARES, 1996, p. 330).

Exemplo 5

\begin{tabular}{|l|c|c|}
\hline \multicolumn{2}{|c|}{ ÚLTIMO CREDO } \\
\hline Como ama o homem adúltero o adultério & $\mathrm{F}$ & $\mathrm{a}$ \\
E o ébrio a garrafa tóxica de rum, & $\mathrm{M}$ & $\mathrm{b}$ \\
Amo o coveiro - este ladrão comum & $\mathrm{M}$ & $\mathrm{b}$ \\
Que arrasta a gente para o cemitério! & $\mathrm{F}$ & $\mathrm{a}$ \\
\hline É o transcendentalíssimo mistério! & $\mathrm{F}$ & $\mathrm{a}$ \\
É o nous, é o pneuma, é o ego sum qui sum, $^{2}$ & $\mathrm{M}$ & $\mathrm{b}$ \\
É a morte, é esse danado número Um $_{\text {Que matou Cristo e que matou Tibério! }}^{\mathrm{M}}$ & $\mathrm{b}$ \\
\hline Creio, como o filósofo mais crente, & $\mathrm{F}$ & $\mathrm{a}$ \\
Na generalidade decrescente & $\mathrm{F}$ & $\mathrm{c}$ \\
Com que a substância cósmica evolui... & $\mathrm{F}$ & $\mathrm{c}$ \\
\hline Creio, perante a evolução imensa, & $\mathrm{M}$ & $\mathrm{d}$ \\
Que o homem universal de amanhã vença & $\mathrm{F}$ & $\mathrm{e}$ \\
O homem particular que eu ontem fui! & $\mathrm{F}$ & $\mathrm{e}$ \\
\hline \multicolumn{2}{|c|}{ Augusto dos Anjos (1884-1914) (PROENÇA, 1997, p. 81) } \\
\hline
\end{tabular}

2 Observe-se, nessas rimas masculinas, a consonância entre palavras monossilábicas de línguas diferentes, português e latim. 
O esquema rimático de tonicidade também está delimitando as estrofes. Com autonomia sintática, todas elas têm seu limite inicial marcado por uma rima feminina; mas a rima indicativa de limite final difere por tipo de estrofe: nos quartetos, é feminina e, nos tercetos, masculina. Além disso, há uma alternância, quanto à tonicidade, das rimas emparelhadas: nos quartetos, dispostas nos versos centrais, estão as rimas masculinas, em que a tônica tem uma duração mais prolongada, como se fosse uma nota musical seguida de um ponto, que indica aumento da duração do som; já nos tercetos, dispostas nos dois versos iniciais, estão as rimas femininas, em que a tônica parece ter uma duração menor pela necessidade de pronunciar-se a sílaba átona final da palavra.

Há ainda outra oposição: nos quartetos, as rimas masculinas são nasais e não finalizam as estrofes; as femininas são orais e arrematam a estrofe. Nos tercetos, as rimas femininas são nasais; as rimas masculinas são orais e arrematam a estrofe e a composição. Observa-se também uma modificação da vogal nas estrofes. Esse procedimento na passagem dos quartetos para os tercetos na modificação da vogal consiste na nasalização da vogal - nas rimas femininas, a vogal oral se torna nasal (é $\Rightarrow e m$ ) - ou desnasalização da vogal - nas rimas masculinas, a vogal nasal se torna oral ( $u m \Rightarrow u$ ). Esse jogo, que mantém semelhanças e diferenças, surpreende, desfazendo expectativas e, portanto, produzindo maior efeito.

No soneto parnasiano apresentado no Exemplo 6, as duas partes são determinadas pela organização rímica, estrófica e sintática. Os quartetos, reunidos numa oitava, formam a primeira parte. Têm autonomia sintática e são simétricos quanto à tonicidade (rimas femininas) e quanto à consonância: seus dois ecos rimáticos, femininos, começam e terminam com o som inicial a. No primeiro deles, apresentam-se um conselho e um desejo (vaticínio) - esses dois atos de fala se enquadram na função conativa da linguagem -, seguidos, como se espera nessas situações, de uma justificativa.

Já nos tercetos, também simétricos e autônomos sintaticamente, repete-se o padrão interestrófico consonântico (cde) e de tonicidade (FFM), com rimas finais masculinas; apresenta-se, no primeiro, como ato de fala, uma louvação, também seguida de uma justificativa, exigida pela situação inesperada, isso é louvar a dor. 
Entre os dois tercetos, o limite também é estabelecido por uma figura de construção, a reiteração da oração optativa que exprime a louvação (Bem haja a dor), colocada no meio do verso final do primeiro terceto e em posição inicial do primeiro verso do segundo terceto.

Exemplo 6

\begin{tabular}{|l|c|c|}
\hline \multicolumn{3}{|c|}{ BÁLSAMO NOS PRANTOS } \\
\hline Chora. Uma grande dor te punja e corte & $\mathrm{a}$ & $\mathrm{F}$ \\
E de prantos te inunde a face austera, & $\mathrm{b}$ & $\mathrm{F}$ \\
Já que uma dor pequena prantos gera & $\mathrm{b}$ & $\mathrm{F}$ \\
Na alma de um fraco, só, por que a suporte. & $\mathrm{a}$ & $\mathrm{F}$ \\
\hline Certo, não torce um coração que é forte, & $\mathrm{a}$ & $\mathrm{F}$ \\
A dor que um frágil coração torcera; & $\mathrm{b}$ & $\mathrm{F}$ \\
Peitos de bronze, não; peitos de cera & $\mathrm{b}$ & $\mathrm{F}$ \\
É que a dor amolece desta sorte. & $\mathrm{a}$ & $\mathrm{F}$ \\
\hline Prantos, bálsamo e alívio de quem chora, & $\mathrm{c}$ & $\mathrm{F}$ \\
Sejam frutos do amor, ou sejam frutos & $\mathrm{d}$ & $\mathrm{F}$ \\
Do ódio, bem haja a dor que os faz chorar! & $\mathrm{e}$ & $\mathrm{M}$ \\
\hline Bem haja a dor que pode, enfim, agora, & $\mathrm{c}$ & $\mathrm{F}$ \\
Na aridez desses olhos sempre enxutos, & $\mathrm{d}$ & $\mathrm{F}$ \\
Duas fontes de lágrimas rasgar. & $\mathrm{e}$ & $\mathrm{M}$ \\
\hline \multicolumn{2}{|c|}{ Raimundo Correia (1859-1911) } \\
(IVO, 1958, p. 60) \\
\hline
\end{tabular}

No Exemplo 7, a tonicidade das rimas revela a estrutura do poema: reiteração do esquema dos quartetos (FMMF), uso exclusivo das rimas femininas no primeiro terceto e uso desses dois tipos de rimas, no segundo terceto. São as rimas femininas, dispostas de forma cruzada, que determinam os limites inicial e final.

Os esquemas rimáticos (consonância e tonicidade) levam à seguinte estrutura da composição, constituida de duas partes: na primeira, que compreende a oitava, com rimas femininas de abertura e de fechamento, está a lembrança do passado (partida da pastorinha) e previsão feita por outrem do seu destino. Os tempos verbais empregados estão no modo indicativo - os pretéritos imperfeito e perfeito e o presente descritivo. 
Exemplo 7

\begin{tabular}{|l|c|c|}
\hline \multicolumn{3}{|c|}{ PASSOS DA CRUZ XII } \\
\hline Ela ia, tranqüila pastorinha, & $\mathrm{F}$ & $\mathrm{a}$ \\
Pela estrada da minha imperfeição. & $\mathrm{M}$ & $\mathrm{b}$ \\
Seguia-a, como um gesto de perdão, & $\mathrm{M}$ & $\mathrm{b}$ \\
O seu rebanho, a saudade minha... & $\mathrm{F}$ & $\mathrm{a}$ \\
\hline "Em longas terras hás de ser rainha" & $\mathrm{F}$ & $\mathrm{a}$ \\
Um dia lhe disseram, mas em vão... & $\mathrm{M}$ & $\mathrm{b}$ \\
Seu vulto perde-se na escuridão... & $\mathrm{M}$ & $\mathrm{b}$ \\
Só sua sombra ante meus pés caminha... & $\mathrm{F}$ & $\mathrm{a}$ \\
\hline Deus te dê lírios em vez desta hora, & $\mathrm{F}$ & $\mathrm{c}$ \\
E em terras longe do que eu hoje sinto & $\mathrm{F}$ & $\mathrm{d}$ \\
Serás, rainha não, mas só pastora - & $\mathrm{F}$ & $\mathrm{c}$ \\
\hline Só sempre a mesma pastorinha a ir, & $\mathrm{M}$ & $\mathrm{e}$ \\
E eu serei teu regresso, esse indistinto & $\mathrm{F}$ & $\mathrm{d}$ \\
Abismo entre o meu sonho e o meu porvir... & $\mathrm{M}$ & $\mathrm{e}$ \\
\hline \multicolumn{2}{|c|}{ Fernando Pessoa, ele-mesmo (1888-1935) } \\
\hline \multicolumn{2}{|c|}{ (MONTEIRO, 1970, p. 22) } \\
\hline
\end{tabular}

Essa parte, com a autonomia sintática dos quartetos, contém duas subpartes: a ida da pastorinha e a reação provocada nos outros e no poeta, cada uma das quais apresentando o jogo das rimas reiteradas num mesmo esquema: as rimas femininas delimitam cada quarteto, abraçando ass rimas centrais masculinas.

A segunda parte, que se conecta à primeira pela mudança de tom e de ato de fala (da apresentação do fato real aos fatos desejados), contém uma antevisão do futuro em forma optativa (revelada, no verso 9, pela utilização do presente do subjuntivo em frase optativa) e profética (uso do futuro do presente do indicativo, simples). Nela opõem-se as duas figuras (a pastorinha X eu poético ) apresentadas em forma dos sujeitos sintáticos ( $t u$ elíptico, marcado na forma verbal serás e eu explícito). Essa oposição se marca pela reiteração da conjunção coordenativa aditiva (e) nos versos 10 e 13, pelas flexões das formas verbais (serás/serei), pela rima masculina como limite final de subparte (verso 12) e pela rima feminina inicial (verso 13), fechando-se a composição com uma rima masculina, o que só ocorre no último terceto. 
Nem sempre, porém, se mantém a razão $8: 6$, apresentada nos exemplos anteriores, cuja ocorrência é determinada pela coincidência das partes com as estrofes do soneto primitivo - a oitava e o sexteto. No Exemplo 8, um soneto de Camões, composto na forma canônica italiana, estrutura-se em duas partes, estabelecendo-se, entre os versos, uma razão de 11 : 3. Como todas as rimas são femininas, é a consonância que vai orientar a segmentação, podendo-se, no entanto, fazer aplicação de critérios de outra natureza, como a pontuação.

A primeira parte é constituída de três estrofes (quartetos e primeiro terceto) e 11 versos. Organiza-se semanticamente por uma enumeração de pormenores descritivos (elementos observáveis e nãoobserváveis), destacados por um sinal de pontuação - o ponto-evírgula -, correspondendo à função referencial da linguagem.

Exemplo 8

\begin{tabular}{|l|c|}
\hline \multicolumn{2}{|c|}{ Um mover de olhos, brando e piedoso } \\
\hline Um mover de olhos, brando e piedoso, & a \\
sem ver de quê; um riso brando e honesto, & b \\
quase forçado; um doce e humilde gesto, & b \\
de qualquer alegria duvidoso; & a \\
\hline um despejo quieto e vergonhoso; & a \\
um repouso gravíssimo e modesto; & b \\
uma pura bondade, manifesto & b \\
indício da alma, limpo e gracioso; & a \\
\hline um encolhido ousar; uma brandura; & c \\
um medo sem ter culpa; um ar sereno; & d \\
um longo e obediente sofrimento: & e \\
\hline Esta foi a celeste formosura & c \\
da minha Circe, e o mágico veneno & d \\
que pôde transformar meu pensamento. & e \\
\hline \multicolumn{2}{|c|}{ Luís de Camões (c.1527-1580) (LUCAS, 1942, p. 80) } \\
\hline
\end{tabular}

Essa primeira parte se separa da segunda, constituída apenas do segundo terceto, também por um sinal de pontuação, os doispontos, sinal delimitador de parte. Nesse caso, estabelece-se uma relação de dependência entre as duas partes e indica-se uma mudança do ato de fala: passa-se da enumeração descritiva para a dedução (síntese do retrato), apresentada com um substantivo abstrato formosura (efeito desse retrato). A segunda parte, constituída do 
segundo terceto, se apresenta como a chave-de-ouro, sendo, portanto, conclusiva.

Quando não há consonância, como no Exemplo 9, em que ou não há rimas ou as rimas são toantes - pares de rimas toantes, baseadas na vogal a (marcadalfunerária; hectarelar; petrificada/lápide; lápide/ar) -, o jogo da tonicidade pode coincidir com a construção sintática do período: as rimas masculinas e femininas comprovam o papel estruturante na delimitação do período, da estrofe e do texto, caso em que fornece pistas para a identificação dos segmentos em que se pode dividir a unidade textual.

Exemplo 9

\begin{tabular}{|c|c|}
\hline \multicolumn{2}{|c|}{ SONETO À BAILARINA MORTA } \\
\hline $\begin{array}{l}\text { Esfera em equilíbrio, ela dançou } \\
\text { vestida de crepúsculo, marcada } \\
\text { pelo estigma da valsa funerária. } \\
\text { E, dominando o espaço, estremeceu }\end{array}$ & $\begin{array}{l}\mathbf{M} \\
\mathbf{F} \\
\mathbf{F} \\
\mathbf{M}\end{array}$ \\
\hline $\begin{array}{l}\text { as colunas marmóreas do edifício. } \\
\text { Circunscritos no círculo de fogo, } \\
\text { os passos invadiram o hectare } \\
\text { do sono, projetando a silhueta }\end{array}$ & $\begin{array}{l}\mathbf{F} \\
\mathbf{F} \\
\mathbf{F} \\
\mathbf{F}\end{array}$ \\
\hline $\begin{array}{l}\text { - miniatura de pássaro a voar. } \\
\text { E valsou... E valsou por sobre rosas... } \\
\text { Inebriada de sons, ela estancou, }\end{array}$ & $\begin{array}{l}\mathrm{M} \\
\mathrm{F} \\
\mathrm{M}\end{array}$ \\
\hline $\begin{array}{l}\text { vacilou e caiu petrificada. } \\
\text { - Sua carne ficou por sobre a lápide } \\
\text { e sua alma se foi bailando no ar. }\end{array}$ & $\begin{array}{l}\mathrm{F} \\
\mathrm{E} \\
\mathrm{M}\end{array}$ \\
\hline $\begin{array}{l}\text { Francisco Valois (*1932) } \\
\text { (VALOIS, 2001, p. 67-68) }\end{array}$ & \\
\hline
\end{tabular}

O soneto se compõe de cinco períodos, marcados pelo ponto de fechamento. Os dois primeiros períodos coordenam-se sindeticamente com a conjunção aditiva (e), formando um subconjunto constituído de cinco versos, com rima inicial masculina e rima final feminina. O terceiro período é constituído de quatro versos, com rima inicial feminina e final masculina. O quarto período tem três versos, com rima inicial e final femininas, cruzadas. E o último período tem dois versos com rimas de tonicidade diferente: inicial 
esdrúxula e final masculina. A composição inicia e termina com rimas masculinas.

Observa-se que esses períodos se agrupam em estrofes de um número decrescente de versos, $5 \rightarrow 4 \rightarrow 3 \rightarrow 2$, numa perspectiva vertical, que sugere a queda da bailarina. Esse fato possibilita a reescrita apresentada no Quadro 1, em que cada estrofe apresenta um verso a menos do que a que lhe é imediatamente anterior.

Quadro 1 - Reescrita heteroestrófica do Exemplo 9

\begin{tabular}{|l|l|l|l|}
\hline PERIODO & VERSOS & RIMAS & ESTROFE \\
\hline $1-2$ & Esfera em equilíbrio, ela dançou & $\mathrm{M}$ & QUINTETO \\
& vestida de crepúsculo, marcada & $\mathrm{F}$ & \\
& pelo estigma da valsa funerária. & $\mathrm{F}$ & \\
& E, dominando o espaço, estremeceu & $\mathrm{M}$ & \\
& as colunas marmóreas do edifício. & $\mathrm{F}$ & \\
\hline 3 & $\begin{array}{l}\text { Circunscritos no círculo de fogo, } \\
\text { os passos invadiram o hectare }\end{array}$ & $\mathrm{F}$ & QUARTETO \\
& do sono, projetando a silhueta & $\mathrm{F}$ & \\
& - miniatura de pássaro a voar. & $\mathrm{F}$ & \\
\hline 4 & E valsou... E valsou por sobre rosas... & $\mathrm{F}$ & TERCETO \\
& Inebriada de sons, ela estancou, & $\mathrm{M}$ & \\
& vacilou e caiu petrificada. & \\
\hline 5 & - Sua carne ficou por sobre a lápide & $\mathrm{F}$ & DíSTICO \\
& e sua alma se foi bailando no ar. & $\mathrm{M}$ & \\
\hline
\end{tabular}

Também se nota o papel estruturante das rimas na segmentação da composição que, embora reescrita em cinco estrofes, apresenta uma segmentação bipartida, em que os versos apresentam uma razão de $12: 2$ (ou $6: 1$, numa versão simplificada), adotando-se,

3 Não se levou em conta, na contagem dos períodos, esse primeiro fragmento, disposto no início de verso e reiterado no meio do verso, por se tratar de um recurso métrico, uma figura de construção chamada mesarquia (Cf. TAVARES, 1996, p. 334). Considerou-se também essa seqüência de coordenadas, como um único período, para evitar um verso isolado, o que não permitiria a determinação do limite inicial e final. As reticências aqui parecem ter um valor retórico, marcando um período de tempo psicológico, da duração de um movimento que já se sabe anteceder a morte. Se o soneto é dedicado à bailarina morta, o fato já aconteceu e, relembrado, motiva a reflexão sobre a efemeridade das coisas. 
como critério, o ato de fala: narração/descrição e reflexão. A primeira parte se organiza, adotado o critério do conhecimento do mundo, em duas subpartes: o esperado, o movimento simétrico da bailarina; e o inesperado (sua queda e morte). Nessas subpartes, o elemento focalizado é visto ora como um todo, ora como parte, numa visão sinedóquica (Quadro 2).

Quadro 2 - Segmentação bipartida do texto do Exemplo 9

\begin{tabular}{|c|c|c|c|c|}
\hline ATO & PARTE & A bailarina & PERIOODOS & Limite \\
\hline \multirow[t]{4}{*}{$\begin{array}{l}\text { I. Narração/ } \\
\text { Descrição }\end{array}$} & \multirow{3}{*}{$\begin{array}{l}\text { A. } \\
\text { O esperado: } \\
\text { Dança } \\
\text { c } \\
\text { Vida }\end{array}$} & $\begin{array}{l}\text { 1. O todo: } \\
\text { a) ação }\end{array}$ & $\begin{array}{l}\text { Esfera em equilíbrio, ela dançou } \\
\text { vestida de crepúsculo, marcada } \\
\text { pelo estigma da valsa funerária. }\end{array}$ & M \\
\hline & & b) efeito & $\begin{array}{l}\text { E, dominando o espaço, estremeceu } \\
\text { as colunas marmóreas do edifício. }\end{array}$ & $\begin{array}{l}\mathrm{M} \\
\mathrm{F}\end{array}$ \\
\hline & & 2. A Parte & $\begin{array}{l}\text { Circunscritos no círculo de fogo, } \\
\text { os passos invadiram o hectare } \\
\text { do sono, projetando a silhueta } \\
\text { - miniatura de pássaro a voar. }\end{array}$ & $\mathrm{F}$ \\
\hline & \multirow{2}{*}{$\begin{array}{l}\text { B } \\
\text { O inesperado: } \\
\text { Queda } \\
\mathrm{e} \\
\text { Morte }\end{array}$} & 1) O todo & $\begin{array}{l}\text { E valsou... }{ }^{4} \text { E valsou por sobre rosas... } \\
\text { Inebriada de sons, ela estancou, } \\
\text { vacilou e caiu petrificada. }\end{array}$ & $\mathrm{F}$ \\
\hline II Reflexão & & 2) A parte & $\begin{array}{l}\text { - Sua carne ficou por sobre a lápide } \\
\text { e sua alma se foi bailando no ar. }\end{array}$ & $\begin{array}{l}\mathrm{E} \\
\mathrm{M}\end{array}$ \\
\hline
\end{tabular}

\section{Segmentação tripartida}

Na estruturação tripartida, a razão entre os versos se faz mais freqüentemente, ou entre uma oitava, uma quadra e um dístico (Exemplo 10), ou entre uma oitava e dois tercetos (Exemplo 11), estrofes relacionadas às formas canônicas do soneto.

O soneto apresentado no Exemplo 10 se estrutura em três partes, o que se percebe pela aplicação do critério rimático

4 Não se levou em conta, na contagem dos períodos, esse primeiro fragmento, disposto no início de verso e reiterado no meio do verso, por se tratar de um recurso métrico, uma figura de construção chamada mesarquia (Cf. TAVARES, 1996, p. 334).

5 Considerou-se também essa seqüência de coordenadas, como um único período, para evitar um verso isolado, o que não permitiria a determinação do limite inicial e final. 
(tonicidade) e sintático (jogo das formas afirmativa e negativa) e do atos de fala (modo imperativo): 1) Ama-me (versos 1-8, em que os quartetos formam uma oitava, com autonomia sintática); 2) Nem me ames (9-12), que correspondem a um quarteto, com autonomia sintática; e 3) Ama-me (v. 13-14, um dístico. Dessa forma, descobre-se um soneto inglês (três quartetos e um dístico) mascarado na apresentação tipográfica de outra forma canônica.. Essas partes estabelecem uma razão entre os versos de $8: 4: 2$, em que cada estrofe tem a metade do número de versos da que a antecede. Isso se comprova na reescrita do Exemplo 10:

Exemplo 10

\begin{tabular}{|l|l|l|}
\hline Ama-me por amor do amor somente & \multicolumn{2}{|l|}{ RIMAS } \\
\hline Ama-me por amor do amor somente & F & a \\
Não digas: “Amo-a pelo seu olhar, & M & b \\
O seu sorriso, o modo de falar & M & b \\
Honesto e brando. Amo-a porque se sente & F & a \\
\hline Minh'alma em comunhão constantemente & F & a \\
Com a sua." Porque pode mudar & M & b \\
Isso tudo, em si mesmo, ao perpassar & M & b \\
Do tempo, ou para ti unicamente. & F & a \\
\hline Nem me ames pelo pranto que a bondade & F & c \\
De tuas mãos enxuga, pois se em mim & M & d \\
Secar, por teu conforto, esta vontade & F & c \\
\hline De chorar, teu amor pode ter fim! & M & e \\
Ama-me por amor do amor, e assim & M & e \\
Me hás de querer por toda a eternidade. & F & d \\
\hline \multicolumn{2}{|c|}{ Elizabeth Barrett Browning (1806-1861) } \\
Trad. de Manuel Bandeira, (BANDEIRA, 1966, p. 450) \\
\hline
\end{tabular}

Reescrita do Exemplo 10

\begin{tabular}{|l|l|l|}
\hline Ama-me por amor do amor somente \\
\hline Ama-me por amor do amor somente & $\mathrm{F}$ & $\mathrm{a}$ \\
Não digas: "Amo-a pelo seu olhar, & $\mathrm{M}$ & $\mathrm{b}$ \\
O seu sorriso, o modo de falar & $\mathrm{M}$ & $\mathrm{b}$ \\
Honesto e brando. Amo-a porque se sente & $\mathrm{F}$ & $\mathrm{a}$ \\
Minh'alma em comunhão constantemente & $\mathrm{F}$ & $\mathrm{a}$ \\
Com a sua." Porque pode mudar & $\mathrm{M}$ & $\mathrm{b}$ \\
Isso tudo, em si mesmo, ao perpassar & $\mathrm{M}$ & $\mathrm{b}$ \\
Do tempo, ou para ti unicamente. & $\mathrm{F}$ & $\mathrm{a}$ \\
\hline
\end{tabular}




\begin{tabular}{|l|l|l|}
\hline Nem me ames pelo pranto que a bondade & F & c \\
De tuas mãos enxuga, pois se em mim & M & d \\
Secar, por teu conforto, esta vontade & F & c \\
De chorar, teu amor pode ter fim! & M & e \\
\hline Ama-me por amor do amor, e assim & M & e \\
Me hás de querer por toda a eternidade. & F & d \\
\hline
\end{tabular}

Além dessa estruturação identificada por um recurso morfossintático, a tonicidade das rimas orienta a segmentação do texto. As duas primeiras estrofes, que formam a primeira parte, têm rimas femininas delimitadoras. A segunda parte, constituída do primeiro terceto e do primeiro verso do último terceto, abre-se com uma rima feminina e fecha-se com uma rima masculina. Assim, pela repetição da rima feminina final, determinam-se o limite final da primeira parte e o limite inicial da segunda. A terceira parte abre-se com uma rima masculina e fecha-se com a rima feminina. A repetição da rima masculina é um marco de delimitação de partes. Mais uma vez, o jogo poético se revela como o uso de variações de um mesmo procedimento selecionado. Embora nesse poema, coexistam os dois esquemas consonântico e de tonicidade, é a tonicidade que orienta a segmentação.

No Exemplo 11, há uma parte narrativa, expressa nos dois quartetos, que formam uma oitava, em que, pela reiteração do esquema rimático de rimas masculinas abraçadas, determinam-se os seus limites iniciais. A segunda parte, descritiva, destaca-se da primeira pela utilização de rimas femininas seqüienciadas, tendo-se também marcado o seu final pela pontuação (dois-pontos). Isso porque tudo o que se diz nas estrofes anteriores, primeiro membro dos dois pontos, consiste na enumeração de fatos observados a que se acrescentam alguns breves comentários descritivos e avaliativos. No segundo terceto, porém, apresenta-se um fato, que destoa dos anteriores, pelo seu tom declamatório e quase apoteótico - uma citação direta, marcada pelo uso das aspas -, a que se acrescenta o comentário irônico e depreciativo de um eu lírico irritado e impaciente com o que vê e ouve. A razão entre os versos das partes é, pois, de 8 : $3: 3$.

Observe-se a seleção lexical que deprecia - "sujeito" -, de cuja boca sai, pela utilização do discurso direto, a bela construção 
alencarina que, infelizmente, se tornou chavão, caindo na boca até daqueles que jamais leram Alencar, como lamenta o poeta.

Exemplo 11

\begin{tabular}{|l|l|l|}
\hline \multicolumn{3}{|c|}{ VERDES MARES } \\
\hline Clama uma voz amiga: - "Aí tem o Ceará." & M & a \\
E eu, que nas ondas punha a vista deslumbrada, & F & b \\
Olho a cidade. Ao sol chispa a areia doirada. & F & b \\
A bordo a faina avulta e toda a gente já & M & a \\
\hline Desce. Uma moça ri, quebrando o panamá. & M & a \\
"- Perdi a mala!" um diz de cara acabrunhada. & F & b \\
Sobre as águas, arfando, uma breve jangada & F & b \\
Passa. Tão frágil! Deus a leve, onde ela vá. & M & a \\
\hline Esmalta ao fundo a costa a verdura de um parque, & F & c \\
E enquanto a grita aumenta em berros e asssobios & F & d \\
Rudes, na confusão brutal do desembarque: & F & c \\
\hline Fitando a vastidão magnífica do mar, & M & e \\
Que ressalta e reluz: - "Verdes mares bravios..." & F & d \\
Cita um sujeito que jamais leu Alencar. & M & e \\
\hline \multicolumn{2}{|c|}{ Manuel Bandeira (1886-1968) } \\
(BANDEIRA, 1966, p. 56-57) & \\
\hline
\end{tabular}

Contudo, outras razões entre os tipos de estrofe, decorrentes da segmentação tripartida da composição, podem ser verificadas, como se comprova no Exemplo 12, em que o valor estruturante das rimas se dá nos quartetos com rimas femininas e masculinas cruzadas no primeiro; e com rimas femininas, no segundo. Também têm um papel estruturante, nesses quartetos, as duas palavras-rimas ("sol" e "sorriso"), intrastróficas, dispostas nos versos pares, servindo de fechamento para cada uma dessas estrofes. No entanto, formam versos diferentes quanto à tonicidade - masculinos e femininos.

Exemplo 12

\begin{tabular}{|l|l|l|}
\hline FOI UM DIA DE INÚTEIS AGONIAS & \multicolumn{2}{|c|}{ RIMAS } \\
\hline Foi um dia de inúteis agonias. & F & $\mathbf{a}$ \\
Dia de sol, inundado de sol!... & M & b \\
Fulgiam nuas as espadas frias.. & $\mathbb{F}$ & $\mathbf{a}$ \\
Dia de sol, inundado de sol!... & M & b \\
\hline
\end{tabular}




\begin{tabular}{|l|l|l|}
\hline Foi um dia de falsas alegrias. & F & a \\
Dália a esfolhar-se, - o seu mole sorriso... & F & c \\
Voltavam os ranchos das romarias, & F & a \\
Dália a esfolhar-se, - o seu mole sorriso... & F & c \\
\hline Dia impressível mais que os outros dias & F & a \\
Tão lúcido... Tão pálido... Tão lúcido!... & E & d \\
Difuso de teoremas, de teorias... & F & a \\
\hline O dia fútil mais que os outros dias! & F & a \\
Minuete de discretas ironias... & F & a \\
Tão lúcido... Tão pálido... Tão lúcido!... & E & d \\
\hline Camilo Pessanha (1867-1926) & \\
(VIDIGAL, 1965, p. 24) & \\
\hline
\end{tabular}

Nos tercetos, as palavras rimas (dias, lúcido) são interestróficas: a primeira inicia cada terceto, em versos femininos; a segunda, proparoxitona, forma versos esdrúxulos, formando um eco rinático com rima distanciada entre dois versos que se repetem integralmente (segundo verso do primeiro terceto e último verso do segundo terceto). Fecha-se, assim, a composição com um ritornelo.

Esse recurso leva à possibilidade de estruturar essa composição em três estrofes: a primeira, um quarteto, com rimas cruzadas, iniciado com o som $a$ e terminado com o som b, iniciado com rima feminina e terminado com rima masculina; seguem dois quintetos, o primeiro, só com rimas femininas, iniciado e terminado com o som $a$, com rimas cruzadas; o segundo, iniciado e terminado com o som $d$, e com o mesmo verso, com rimas distanciadas que abraçam três rimas emparelhadas seqüenciadas iniciado e terminado com rimas esdrúxulas que abraçam rimas femininas.

A razão entre os versos das partes é $4: 5: 5$, comprovada na reescrita desse exemplo.

Reescrita do Exemplo 12

\begin{tabular}{|l|l|l|}
\hline FOI UM DIA DE INÚTEIS AGONIAS & \multicolumn{2}{|c|}{ RIMAS } \\
\hline Foi um dia de inúteis agonias. & $\mathrm{F}$ & $\mathrm{a}$ \\
Dia de sol, inundado de sol!... & $\mathrm{M}$ & $\mathrm{b}$ \\
Fulgiam nuas as espadas frias.. & $\mathrm{F}$ & $\mathrm{a}$ \\
Dia de sol, inundado de sol!... & $\mathrm{M}$ & $\mathrm{b}$ \\
\hline
\end{tabular}




\begin{tabular}{|l|l|l|}
\hline Foi um dia de falsas alegrias. & F & a \\
Dália a esfolhar-se, - o seu mole sorriso... & F & c \\
Voltavam os ranchos das romarias, & F & a \\
Dália a esfolhar-se, - o seu mole sorriso... & F & c \\
Dia impressível mais que os outros dias & F & a \\
\hline Tão lúcido... Tão pálido... Tão lúcido!... & E & d \\
Difuso de teoremas, de teorias... & F & a \\
O dia fútil mais que os outros dias! & F & a \\
Minuete de discretas ironias... & F & a \\
Tão lúcido... Tão pálido... Tão lúcido!... & E & d \\
\hline Camilo Pessanha (1867-1926) (VIDIGAL, 1965, p. 24) \\
\hline
\end{tabular}

\section{Segmentação quadripartida}

Nessa segmentação, há uma superposição de partes e estrofes, respeitando-se a distribuição tipográfica em que mais freqüentemente se apresenta o soneto. No caso do Exemplo13, em que as rimas são todas femininas, com o critério da consonância se percebe melhor a organização estrutural.

Nessa composição, o poder estruturante da rima faz destacar as quatro estrofes, autônomas sintaticamente. Nos dois quartetos, os ecos rimáticos se apresentam invertidos, em quiasma. Assim, os limites inicial e final apresentam ecos rimáticos diferentes em cada um dos quartetós: o eco rimático $a$, limite inicial, no primeiro e final, no segundo; o eco rimático $b$, limite final no primeiro quarteto e inicial do segundo.

\section{Exemplo 13}

\begin{tabular}{|l|c|}
\hline \multicolumn{2}{|c|}{ DO AZUL, NUM SONETO } \\
\hline Verificar o azul nem sempre é puro. & a \\
Melhor será revê-lo entre as ramadas & b \\
e os altos frutos de um pomar escuro & a \\
- azul de tênues bocas desoladas. & b \\
\hline Melhor será sonhá-lo em madrugadas, & b \\
fresco, inconstante azul sempre imaturo, & a \\
azul de claridades sufocadas & b \\
latejando nas pedras - nascituro. & a \\
\hline Não este azul mas outro e dolorido, & c \\
Evanescente azul que na orvalhada & d \\
ficou, pétala ingênua, torturada. & d \\
\hline
\end{tabular}




\begin{tabular}{|l|l|}
\hline $\begin{array}{l}\text { Recupero-o sem ter e ei-lo perdido, } \\
\text { azul de voz, de sombra envenenada, } \\
\text { que em nós se esvai sem nunca ter vivido. }\end{array}$ & $\begin{array}{l}\text { c } \\
\text { d } \\
\text { c }\end{array}$ \\
\hline \multicolumn{2}{|c|}{ Alphonsus de Guimaraens (1870-1921) } \\
(GRÜNEWALD,1987, p. 201) \\
\hline
\end{tabular}

No primeiro terceto, ainda difere o eco rimático na sua delimitação: o limite inicial apresenta o eco rimático $c$; o limite final é estabelecido pelo eco rimático $d$. No entanto, esse esquema vai ser quebrado, desfazendo-se as expectativas auditivas, pois o último terceto começa e termina com o mesmo eco rimático $c$. O primeiro terceto tem uma disposição de rimas intra-estróficas emparelhadas finais (cdd) inversas à disposição encontrada no soneto francês (ccd emparelhadas iniciais). No segundo terceto, porém, mantém-se a distribuição intra-estrófica cruzada, própria do soneto italiano.

\section{Conclusão}

Diante desses casos apresentados, poemas de diversos autores e de diferentes estilos de época, as rimas quanto à consonância e principalmente quanto à tonicidade não podem ser tratadas, nas composições poéticas, como se fossem apenas um mero recurso mnemônico ou um simples ornamento, que embeleza, mas que pode ser dispensável. O papel estruturante das rimas é fundamental na leitura das formas poéticas, especificamente o soneto.

\section{Referências}

ALVES, Castro. Espumas flutuantes: poemas. São Paulo: O Estado de S. Paulo/Klick Editora (Ler é aprender, n. 1).

AYALA, Walmir. Gregório de Matos: Antologia poética. Seleção de Walmir Ayala; apresentação de Leodegário A. de Azevedo Filho. Rio de Janeiro: Ediouro; São Paulo: Publifolha, 1997 (Biblioteca Folha: 27).

BANDEIRA, Manuel. Estrela da vida inteira: poesias reunidas. Rio de Janeiro: José Olympio, 1966. 
CARRETER, Fernando Lázaro, LARA, Cecília de. Manual de explicação de textos. São Paulo: Editora Centro Universitário, 1962.

GRÜNEWALD, José Lino (Org.). Grandes sonetos da nossa língua. Seleção e organização de José Lino Grünewald. Rio de Janeiro: Nova Fronteira, 1987.

IVO, Lêdo. Raimundo Correia: poesia. Rio de Janeiro: Agir, 1958 (Nossos Clássicos; 20).

LAGARDE, André; MICHARD, Laurent XVII ${ }^{\mathrm{e}}$ siècle: Les grands auteurs français du programme. Paris: Bordas, 1959b (Textes et Littérature).

LUCAS, João de Almeida (Org.). Luís de Camões: sonetos. Prefácio, seleção, notas e bibliografia de João de Almeida Lucas. Lisboa: Livraria Clássica Editora, 1942 (Clássicos Portugueses, Trechos escolhidos, Século XVI - Poesia)

MARTINS, Maria João. Luz e treva: Nuno Júdice. JL, Jornal de Letras, Artes e Idéias, Lisboa, 19 jan - $1^{\circ}$ fev. 2005, Figura, p. 6-7.

MOLINO, Jean; GARDES-TAMINE, Joëlle. Introduction à l'analyse de la poésie: vers et figures. 3. ed. Paris : PUF, 1992.

MOLINO, Jean; GARDES-TAMINE, Joëlle. Introduction à l'analyse de la poésie: de la strophe à la construction du poème. Paris : Presses Universitaires de France, 1988.

MONTEIRO, Adolfo Casais (Org). Fernando Pessoa: poesia. 5. ed. Rio de Janeiro: Agir, 1970 (Nossos Clássicos, 1).

NÓBREGA, Mello. Rima e poesia. Rio de Janeiro: Instituto Nacional do Livro/Ministério da Educação e Cultura, 1965.

PROENÇA, Ivan Cavalcante (Org.) Augusto dos Anjos: antologia poética. Estudo e notas de. Ivan Cavalcante Proença Rio de Janeiro: Ediouro; São Paulo: Publifolha, 1997 (Biblioteca Folha; 24).

TAVARES, Hênio Último da Cunha. Teoria Literária. 11. ed. rev. e atual. Belo Horizonte: Villa Rica, 1996.

VALOIS, Francisco. A noite reinventada. Maceió: Catavento, 2001.

VIDIGAL, Bernardo (Org.). Camilo Pessanha: poesia e prosa. Rio de Janeiro: Agir, 1965 (Nossos Clássicos, 75). 